\title{
Determining inter-fractional motion of the uterus using 3D ultrasound imaging during
} radiotherapy for cervical cancer

\author{
Baker, Mariwan; Jensen, Jørgen Arendt; Behrens, Claus F.
}

\section{Published in:}

Proceedings of SPIE

Link to article, DOI:

$10.1117 / 12.2043173$

Publication date:

2014

Document Version

Early version, also known as pre-print

Link back to DTU Orbit

Citation (APA):

Baker, M., Jensen, J. A., \& Behrens, C. F. (2014). Determining inter-fractional motion of the uterus using 3D ultrasound imaging during radiotherapy for cervical cancer. In Proceedings of SPIE (Vol. 9040). [90400Y] SPIE International Society for Optical Engineering. https://doi.org/10.1117/12.2043173

\section{General rights}

Copyright and moral rights for the publications made accessible in the public portal are retained by the authors and/or other copyright owners and it is a condition of accessing publications that users recognise and abide by the legal requirements associated with these rights.

- Users may download and print one copy of any publication from the public portal for the purpose of private study or research.

- You may not further distribute the material or use it for any profit-making activity or commercial gain

- You may freely distribute the URL identifying the publication in the public portal 


\title{
Determining inter-fractional motion of the uterus using 3D ultrasound imaging during radiotherapy for cervical cancer
}

\author{
Mariwan Baker ${ }^{1,2,3}$, Jørgen Arendt Jensen², and Claus F. Behrens ${ }^{1}$ \\ 1 Department of Oncology, Radiotherapy Research Unit, Herlev Hospital, University of \\ Copenhagen, Herlev, Denmark \\ 2 Center for Fast Ultrasound Imaging, Dept. of Elec. Eng., Technical University of Denmark, \\ DK-2800 Lyngby, Denmark \\ 3 Center for Nuclear Technologies, Technical University of Denmark, DTU Risø Campus, \\ Roskilde, Denmark
}

E-mail: mariwan.baker@regionh.dk

\begin{abstract}
Uterine positional changes can reduce the accuracy of radiotherapy for cervical cancer patients. The purpose of this study was to; 1) Quantify the inter-fractional uterine displacement using a novel 3D ultrasound (US) imaging system, and 2) Compare the result with the bone match shift determined by Cone-Beam CT (CBCT) imaging.Five cervical cancer patients were enrolled in the study. Three of them underwent weekly CBCT imaging prior to treatment and bone match shift was applied. After treatment delivery they underwent a weekly US scan. The transabdominal scans were conducted using a Clarity US system (Clarity ${ }^{\circledR}$ Model 310C00). Uterine positional shifts based on soft-tissue match using US was performed and compared to bone match shifts for the three directions. Mean value $( \pm 1 \mathrm{SD})$ of the US shifts were $(\mathrm{mm})$; anterior-posterior $(\mathrm{A} / \mathrm{P})$ : $(3.8 \pm 5.5)$, superior-inferior $(\mathrm{S} / \mathrm{I})(-$ $3.5 \pm 5.2)$, and left-right $(\mathrm{L} / \mathrm{R}):(0.4 \pm 4.9)$. The variations were larger than the CBCT shifts. The largest interfractional displacement was from $-2 \mathrm{~mm}$ to $+14 \mathrm{~mm}$ in the AP-direction for patient 3 . Thus, CBCT bone matching underestimates the uterine positional displacement due to neglecting internal uterine positional change to the bone structures. Since the US images were significantly better than the CBCT images in terms of soft-tissue visualization, the US system can provide an optional image-guided radiation therapy (IGRT) system. US imaging might be a better IGRT system than CBCT, despite difficulty in capturing the entire uterus. Uterine shifts based on US imaging contains relative uterus-bone displacement, which is not taken into consideration using CBCT bone match.
\end{abstract}

\section{INTRODUCTION}

Local recurrence of cervical cancer remains a challenge worldwide despite using advanced treatment techniques [1]. In addition to surgery and chemotherapy, radiotherapy is an effective treatment modality. However, radiation complications, such as gastrointestinal toxicity, are experienced by patients undergoing radiation treatment [2]. Modern conformal radiotherapy with tight margins and steep dose gradients, such as intensity-modulated radiotherapy (IMRT) and volumetric conformal arc therapy, allows a reduction of undesired radiation doses to healthy organs but requires more precise daily tumour alignment prior to each fraction throughout the entire course of the treatment.

Today's Image Guided Radiation Therapy (IGRT) methods, such as the electronic portal image device (EPID) and the $\mathrm{kV}$ volumetric cone beam CT (CBCT), are widely utilized for daily patient alignment and enable online correction of positional tumor misalignments, thereby improving the precision of the delivery of the prescribed radiation dose to the delineated target [3]. However, the weakness of using these ionizing system are insufficient 
soft tissue visualization, for instance in visualizing the uterus of gynecological (GYN) cancer patients or identifying the prostate gland and surrounding soft tissue organs at risk (OARs) in prostate cancer patients. As a result, bone matching is frequently applied as a daily tumor alignment method in cervical cancer treatment. For cervical cancer patients, large margins are applied around delineated gross tumor volume (GTV), to ensure target radiation dose coverage. The large margin is due to the complexity of the pelvis with its tumor and normal organ motion as well as deformation dynamics, which adversely impacts on the irradiated healthy tissues [4]. Additionally, tumor volume regression is reported to be substantial, with up to $80 \%$ reduction by the end of the treatment period [5-7]. Different imaging methodologies such as implanted fiducial markers as a reference point [8-10] are employed in patients with cervical cancer to determine uterus and/or target motion. Use of the tumor surrogate method limits analysis of uterine shifts, because implanted fiducial markers can fall out, migrate, or be displaced due to tumor shrinkage and organ deformation. On the other hand, MRI imaging provides an outstanding visualization of the uterus and cervix, enabling discrimination from other organs [4, 9, 11]. The application of MRI as IGRT for daily tumor alignment requires MRI/LINAC accessibility, which is costly and rarely used clinically [12-13]. Therefore, various cheaper non-ionized 3D US systems have been developed, such as the 3D Clarity ${ }^{\circledR}$ Soft Tissue Visualization system (Clarity ${ }^{\circledR}$ Model 310C00, Elekta, Montreal, Canada) and the NOMOS B-mode Acquisition and Targeting (BAT) ultrasound system [14-16]. However, these US systems can only be used for cancer sites in a soft tissue environment such as GYN, prostate and postoperative lumpectomy cavity in breast cancer patients. The prostate and uterus, where internal position variations are partly dependent on rectal-bladder filling, are ideal sites for US-scans. Furthermore, different uncertainty factors such as probe handling, image quality, and inter-operator variability are involved in the use of a US system. Inter-operator variations in US transducer probe pressure have been documented earlier for prostate patients [17-18]. In the present study, the main purpose was to quantify the magnitude of the inter-fractional uterine displacement, based on soft tissue match, using a novel 3D US imaging system. A specific purpose was to compare the US results with the bone match shifts determined by means of CBCT imaging.

\section{MATERIALS AND METHODS}

Five cervical cancer patients, mean age 60 years (51/68), were enrolled in this study. All underwent radiotherapy at Herlev hospital. One patient was excluded due to incontinence, while a second was excluded after acquisition of US images in the CT simulation room. The patient in question had a nephrostomy with an implanted catheter, which resulted in very poor image quality.Each of the patients underwent daily EPID and weekly CBCT setup verification imaging. Since the uterus cannot be visualized using either EPID or CBCT, all the shifts are based on bone match. Immediately after treatment the patients underwent a weekly US scan performed by two experienced operators. Seven RTTs participated in an extensive two week training program provided by the commercial vendor as well as several practice sessions prior to the start of the study.

\subsection{Clarity ultrasound system}

The Clarity ultrasound system consists of two US-units: one located in the CT simulation room and the second in the treatment room. The two units are connected through a workstation/server. The treatment room unit is utilized as intra-modality IGRT. Each US unit is equipped with a convex-probe for trans-abdominal 3D US scanning. A ceiling-mounted infrared (IR) camera tracks the US-probe by monitoring the IR-reflectors mounted on each probe (Fig. 1. A). To enable superimposition of the 3D US images of the treatment room onto the reference US image sets of the CT room, the US system is calibrated to the same coordinate system as the CT and treatment rooms. The calibration procedure is accomplished by means of a dedicated alignment phantom provided by the vendor. Quality assurance checks confirm the calibration on each day of use.

\subsection{CT-US simulation and treatment planning}

All the patients underwent a CT scan. Two radiographers with experience of the Clarity system were responsible for each patient. The patient alignment was performed by means of the room lasers. A US image was acquired 
immediately after the CT scan (Fig. 1.A-B). For each scan the US probe was placed in the pubic symphysis region and then rotated/swept followed by a probe slide in the cranial direction. This US image acquisition method is known as the sweep/slide technique and enables capture of the entire uterus. The sweep technique alone is a proper scan on prostate cancer patients, as the prostate is smaller and the entire target can be captured by a transabdominal sweep scan. Firm pressure, which might lead to uterus displacement, was avoided when performing the scan, as the focus was on obtaining clear images to facilitate identification of the complex pelvic structure. Since the CT images were to be superimposed onto US images, the same patient setup is necessary for CT and US scans. All the cervical cancer patients underwent MRI scans after CT image acquisition. The GTVand OARs were delineated on CT-MR fusion image datasets by the gynecological oncologist. The CT datasets were transferred to the planning system for 3D treatment planning.

\subsection{Organ delineation}

Initially the delineated target and normal structures were exported from the treatment planning system to the Clarity workstation. Moreover, the previously delineated bladder and rectum, based on standard MRI, were copied to the CT-US fusion to assist the US based target delineation. Subsequently, the CT-US image fusion was performed and the uterus delineated in the reconstructed 3D US-image data sets. Finally, the delineated uterus, including the cervix, uterine body and fundus, was approved as the Planning Reference Volume (PRV) for subsequent weekly US scans in the treatment room. In this study the assisted segmentation in the Clarity workstation was utilized for uterus delineation. Export/import from the treatment planning system to the Clarity workstation, CT/US fusion and uterus delineation were performed by one of two radiographers or one physicist. In addition, a single operator (MB) conducted a retrospective analysis of the acquired US image sets and delineated the organs.

\subsection{Treatment room}

The patient was prepared for daily treatment by aligning her to the lasers by means of marks on the skin, i.e. to reproduce the patient setup position in the CT-simulation room. In this study and prior to the treatment, the weekly CBCT images were acquired, and clinical alignment was performed based on bone matching. The weekly US scans were performed immediately after acquiring CBCT and treatment delivery. Further, the soft tissue match performed by superimposing the segmented uterus in the 3D US image acquired at the treatment unit onto the reference PRV from the CT-simulation, thus potential uterus shifts, uterine center of mass (COM) shifts, of the target were recorded. Finally, the correlated differences in shifts from the US and CBCT matches were compared.

\subsection{Statistical analysis}

A paired t-test was applied to compare US with CBCT shifts to check probability differences between the paired values of the two samples. This was determined by screening the variation of values within each sample and producing a single digit t-value. Despite the different type of image matching in this test, soft tissue versus bone matches, the t-test is applicable, since the aim was to investigate inter-fractional displacements using two different imaging modalities. Furthermore, the p-values were calculated for a 95\% confidence interval (CI). Due to the low number of patients the t-test assumption of normal distribution must be treated with caution.

\section{RESULTS}

Positional uterine center of mass (COM) shifts detected by ultrasound imaging and shifts based on bone alignment using CBCT images in three orthogonal directions are presented in Fig. 2. Positive shifts are anterior, inferior and right. The figure shows 14 scans of each CBCT and US for the three patients, patient 1 five scans, patient 2 four scans, and patient 3 five scans. The plot reveals larger displacement shifts for US than CBCT, especially in the case of patient 2. This can be explained by the fact that US soft tissue matching takes uterus to bone shifts into account compared to only bone matching using CBCT. In this study a great effort was made to perform soft tissue matching based on acquired CBCT, but it was not possible due to poor image quality and thus discrimination of the soft tissue organs was almost impossible. As a result all the performed CBCT matches are 
based on bone match. The difference between US and CBCT can be clearly observed by examining the box-plots of the shifts for each patient (Fig. 3 A, B, C). These differences are obvious for patients 1 and 2 in the AP- and SIdirections, while for patients 2 and 3 the larger deviations can be seen in the LR-direction. In the plot for the three patients based on a total of 14 scans, the larger deviation was visible in US scans in all three directions (Fig. 3 D). The overall mean $( \pm 1 \mathrm{SD})$ of the weekly uterine COM-shifts (US) and bone match shifts (CBCT) was (mm); US/CBCT: AP (3.8 \pm 5.5$) /(2.8 \pm 2.0)$, SI $(-3.0 \pm 5.2) /(2.8 \pm 2.0)$, LR $(-2.7 \pm 1.7) /(-1.0 \pm 3.3)$, respectively (Table.1). The results demonstrate that inter-fractional displacements are greater with US than CBCT. The largest inter-fractional displacement using US was from $-2 \mathrm{~mm}$ to $+14 \mathrm{~mm}$ in the AP-direction for patient 3 , while with CBCT the largest shift was from $-5 \mathrm{~mm}$ to $+5 \mathrm{~mm}$ in the LR-direction also for patient 3 .

The t-values and mean of differences were individually calculated for each patient, while the overall values for all three directions were estimated by means of the paired t-test (Table. 2). No significant differences between US and CBCT shifts $(p>0.05)$ were found in any direction, which might be explained by the low number of scans. The largest lower/upper range of 95\% CI was in the LR-direction in patient $3(-6.7$ to +10.8$)$.

\section{DISCUSSION}

Inter-fractional positional uncertainty of the uterus, rectum and bladder in GYN patients has been a challenge in radiotherapy, leading to the application of larger set-up margins to account for target displacement. Modern conformal treatment (IMRT and volumetric modulated arc therapies) enables better dose conformity, and thus steeper dose gradients. The delineated target and OARs are more susceptible to daily uterine positional displacements and rectal-bladder filling variations. These variations should be taken into account prior to each treatment throughout the course of treatment. The challenge involved in using CBCT and EPID, the most common IGRT imaging modalities today, is the difficulty identifying the soft tissue organs in the pelvis, due to the inability of these systems to visualize soft tissue, making it difficult to compensate for daily internal shifts. In most radiotherapy centers the daily target alignment of cervical cancer patients is based on bone matching, which is also standard in our department. However, bone matching does not take the relative uterine positional displacement into account.

Recently, 3D US has been more frequently applied as an IGRT method and mainly used for prostate alignment prior to the treatment fraction [19-20]. The advantage of ultrasound imaging is believed to be the capacity of this method to visualize soft tissue in the pelvis, especially on the bladder-uterus and bladder-prostate intersections. Very few published papers have reported the application of 3D US in GYN patients [21]. The published data in this study mostly quantifies inter-fractional bladder motion and variations in bladder volume rather than uterine positional changes. For instance, in a US study of 24 patients, Ahmed et al. (2008) concluded that the bladder volume decreased dramatically by a mean of $71 \%$ compared to the planning CT scan. This phenomenon was also observed in our study. Fig. 5 illustrates the reduction in bladder volume from the start of the treatment until week 5, the final week of treatment, despite the fact that the patients adhered to a standard bladder-rectum filling protocol. A moderately full bladder provides better propagation of US-waves and hence a clearer US image by sharpening the interface between bladder and uterus. Bladder volume reduction presents a challenge as it affects the daily uterine and bladder position as well as making the use of ultrasound as a daily IGRT modality more difficult. Tumor regression during radiotherapy is also a challenge. In a study based on weekly CT image acquisition, Lee’s group [9] found an average tumor volume reduction greater than $27 \%$ in the third week compared to the initial CT planning image set.

A number of US studies on the prostate conclude that one of the drawbacks of using 3D US such as the IGRT method is probe pressure induced uncertainty on the target and OARs. In one study, Chan et al.'s 2008 [4] MRIbased study divided the uterus into three sections; cervical os, uterine canal, and uterine fundus. They reported that the fundus can vary from day to day by over $24 \mathrm{~mm}$. Our result from patient 3 revealed an inter-fractional displacement of the uterine center of mass by $16 \mathrm{~mm}$ in the AP-direction, which supports the result of Chan et al. The recent study by Jurgenliemk-Schultz et al. [22], which investigated vaginal positional change and the correlation between vaginal shift and bladder-rectal filling, reported a daily vaginal CTV positional change of up to $23 \mathrm{~mm}$ in the AP-direction. In the present study we observed that the inter-fractional variation was larger with US than CBCT. This can be explained by the fact that CBCT is based on bone matching, which does not take the effect of the relative uterine displacement on the bone structure into account. Initially, the goal of acquiring 3D CBCT in this study was to 
perform soft tissue matches. However, the poor image quality was an obstacle to distinguishing the target from the organs. White et al. conducted a study [23] of inter-observer variations in delineation of the prostate, based on five CBCT scans performed by five genitourinary oncologists. They found that the standard deviation for volume determination of the prostate was $8.93 \mathrm{~cm}^{3}$ with large variability $\left(3.98-19.00 \mathrm{~cm}^{3}\right)$, but the average standard deviation for center of mass displacement was small, measuring 0.7, 1.8, and $2.8 \mathrm{~mm}$ in the LR, AP, and SI-directions. Despite disagreement about how best to delineate the prostate gland, the small inter-observer variability in COM displacement suggests the potential of CBCT as soft tissue image guidance, thus replacing the tumor surrogate method of implanted fiducial markers. However, it should be noted that the study was conducted on a small number of scans and the matches were performed by expert observers, which is not a clinical reality today. Since the pelvis of GYN patients is more complex due to multiple structures moving relative to each other as well as deformation and tumor regression during radiation therapy, replicating the study on GYN patients is almost impossible.

In the present study some of the operators experienced difficulty applying the sweep/slide technique for capturing the entire uterus. First of all, the bladder must be identified, which is always easier in the sagittal plane and then the probe rotated by 90 degrees to the transversal plane, in which the scan was performed. An auto-scan probe would be a better solution, since after identifying the uterus in sagittal plane through a single click, the US scan and reconstruction of the uterine region could be conducted. Another challenge was the decrease in bladder filling during the treatment period, which adversely affected the image quality. This made it more difficult to identify the uterinebladder interface and thus inducing errors in determining the uterine position and consequently variations in the inter-fractional displacements.

\section{CONCLUSION}

US imaging might be a better IGRT system than CBCT, despite difficulty in capturing the entire uterus. Uterine shifts based on US imaging contains relative uterus-bone displacement, which is not taken into consideration using CBCT bone match. A trial study based on more patients is required to validate statistical differences between CBCT and US.

\section{CONFLICT OF INTEREST}

The present study is a part of a three year PhD research project at Herlev Hospital, which is fully funded by Elekta, Inc.

\section{Acknowledgement}

Warm thanks to my hard-working colleagues, who helped me to accomplish this study; Gullander L. (RTT), Pedersen S. K (RTT), Zarp T (RTT), Jacobsson S (RTT), Pazhang S (radiographer), and Lynnerup V. K (radiographer).

\section{References}

[1] P. J. Eifel, a Jhingran, J. Brown, C. Levenback, and H. Thames, "Time course and outcome of central recurrence after radiation therapy for carcinoma of the cervix.,” Int. J. Gynecol. Cancer, vol. 16, no. 3, pp. 1106-11, 2006.

[2] J. K. Salama, A. J. Mundt, J. Roeske, and N. Mehta, "Preliminary outcome and toxicity report of extended-field, intensity-modulated radiation therapy for gynecologic malignancies.,” Int. J. Radiat. Oncol. Biol. Phys., vol. 65, no. 4, pp. 1170-6, Jul. 2006.

[3] T. R. Mackie, J. Kapatoes, K. Ruchala, W. Lu, C. Wu, G. Olivera, L. Forrest, W. Tome, J. Welsh, R. Jeraj, P. Harari, P. Reckwerdt, B. Paliwal, M. Ritter, H. Keller, J. Fowler, and M. Mehta, "Image guidance for precise conformal radiotherapy,” Int. J. Radiat. Oncol., vol. 56, no. 1, pp. 89-105, May 2003.

[4] P. Chan, R. Dinniwell, M. a Haider, Y.-B. Cho, D. Jaffray, G. Lockwood, W. Levin, L. Manchul, A. Fyles, and M. Milosevic, "Inter- and intrafractional tumor and organ movement in patients with cervical cancer undergoing 
radiotherapy: a cinematic-MRI point-of-interest study.,” Int. J. Radiat. Oncol. Biol. Phys., vol. 70, no. 5, pp. 1507-15, Apr. 2008.

[5] K. Lim, P. Chan, R. Dinniwell, A. Fyles, M. Haider, Y.-B. Cho, D. Jaffray, L. Manchul, W. Levin, R. P. Hill, and M. Milosevic, "Cervical cancer regression measured using weekly magnetic resonance imaging during fractionated radiotherapy: radiobiologic modeling and correlation with tumor hypoxia.,” Int. J. Radiat. Oncol. Biol. Phys., vol. 70, no. 1, pp. 126-33, Jan. 2008.

[6] B. M. Beadle, A. Jhingran, M. Salehpour, M. Sam, R. B. Iyer, and P. J. Eifel, "Cervix regression and motion during the course of external beam chemoradiation for cervical cancer.,” Int. J. Radiat. Oncol. Biol. Phys., vol. 73, no. 1, pp. 235-41, Jan. 2009.

[7] H. Nam, W. Park, S. J. Huh, D. S. Bae, B. G. Kim, J. H. Lee, J. W. Lee, D. H. Lim, Y. Han, H. C. Park, and Y. C. Ahn, "The prognostic significance of tumor volume regression during radiotherapy and concurrent chemoradiotherapy for cervical cancer using MRI.,” Gynecol. Oncol., vol. 107, no. 2, pp. 320-5, Nov. 2007.

[8] R. O. S. J. P. K. Aatee, M. A. J. J. O. Lofsen, M. A. B. J. V Erstraate, S. A. Q. Uint, and B. E. N. J. M. H. Eijmen, "DETECTION OF ORGAN MOVEMENT IN CERVIX CANCER PATIENTS USING A FLUOROSCOPIC ELECTRONIC PORTAL IMAGING DEVICE AND RADIOPAQUE MARKERS,” vol. 54, no. 2, pp. 576-583, 2002.

[9] J. E. Lee, Y. Han, S. J. Huh, W. Park, M. G. Kang, Y. C. Ahn, and D. H. Lim, "Interfractional variation of uterine position during radical RT: weekly CT evaluation.,” Gynecol. Oncol., vol. 104, no. 1, pp. 145-51, Jan. 2007.

[10] X. A. Li, X. S. Qi, M. Pitterle, K. Kalakota, K. Mueller, B. a Erickson, D. Wang, C. J. Schultz, S. Y. Firat, and J. F. Wilson, "Interfractional variations in patient setup and anatomic change assessed by daily computed tomography.,” Int. J. Radiat. Oncol. Biol. Phys., vol. 68, no. 2, pp. 581-91, Jun. 2007.

[11] L. van de Bunt, I. M. Jürgenliemk-Schulz, G. a P. de Kort, J. M. Roesink, R. J. H. a Tersteeg, and U. a van der Heide, "Motion and deformation of the target volumes during IMRT for cervical cancer: what margins do we need?,” Radiother. Oncol., vol. 88, no. 2, pp. 233-40, Aug. 2008.

[12] J. J. W. Lagendijk, B. W. Raaymakers, A. J. E. Raaijmakers, J. Overweg, K. J. Brown, E. M. Kerkhof, R. W. van der Put, B. Hårdemark, M. van Vulpen, and U. a van der Heide, "MRI/linac integration.," Radiother. Oncol., vol. 86, no. 1, pp. 25-9, Jan. 2008.

[13] E. M. Kerkhof, B. W. Raaymakers, U. a van der Heide, L. van de Bunt, I. M. Jürgenliemk-Schulz, and J. J. W. Lagendijk, "Online MRI guidance for healthy tissue sparing in patients with cervical cancer: an IMRT planning study.,” Radiother. Oncol., vol. 88, no. 2, pp. 241-9, Aug. 2008.

[14] S. J. Feigenberg, K. Paskalev, S. McNeeley, E. M. Horwitz, A. Konski, L. Wang, C. Ma, and A. Pollack, "Comparing computed tomography localization with daily ultrasound during image-guided radiation therapy for the treatment of prostate cancer: a prospective evaluation.,” J. Appl. Clin. Med. Phys., vol. 8, no. 3, p. 2268, Jan. 2007.

[15] J. Boda-Heggemann, F. M. Köhler, B. Küpper, D. Wolff, H. Wertz, S. Mai, J. Hesser, F. Lohr, and F. Wenz, "Accuracy of ultrasound-based (BAT) prostate-repositioning: a three-dimensional on-line fiducial-based assessment with cone-beam computed tomography.,” Int. J. Radiat. Oncol. Biol. Phys., vol. 70, no. 4, pp. 124755, Mar. 2008. 
[16] F. L. B. Cury, G. Shenouda, L. Souhami, M. Duclos, S. L. Faria, M. David, F. Verhaegen, R. Corns, and T. Falco, "Ultrasound-based image guided radiotherapy for prostate cancer: comparison of cross-modality and intramodality methods for daily localization during external beam radiotherapy.,” Int. J. Radiat. Oncol. Biol. Phys., vol. 66, no. 5, pp. 1562-7, Dec. 2006.

[17] J. P. McGahan, J. Ryu, and M. Fogata, "Ultrasound probe pressure as a source of error in prostate localization for external beam radiotherapy.,” Int. J. Radiat. Oncol. Biol. Phys., vol. 60, no. 3, pp. 788-93, Nov. 2004.

[18] C. F. Serago, S. J. Chungbin, S. J. Buskirk, G. a Ezzell, a C. Collie, and S. a Vora, "Initial experience with ultrasound localization for positioning prostate cancer patients for external beam radiotherapy.," Int. J. Radiat. Oncol. Biol. Phys., vol. 53, no. 5, pp. 1130-8, Aug. 2002.

[19] T. J. Scarbrough, N. M. Golden, J. Y. Ting, C. D. Fuller, A. Wong, P. a Kupelian, and C. R. Thomas, "Comparison of ultrasound and implanted seed marker prostate localization methods: Implications for imageguided radiotherapy.,” Int. J. Radiat. Oncol. Biol. Phys., vol. 65, no. 2, pp. 378-87, Jun. 2006.

[20] C. F. Serago, S. J. Buskirk, T. C. Igel, A. a Gale, N. E. Serago, and J. D. Earle, "Comparison of daily megavoltage electronic portal imaging or kilovoltage imaging with marker seeds to ultrasound imaging or skin marks for prostate localization and treatment positioning in patients with prostate cancer.," Int. J. Radiat. Oncol. Biol. Phys., vol. 65, no. 5, pp. 1585-92, Aug. 2006.

[21] R. Ahmad, M. S. Hoogeman, S. Quint, J. W. Mens, I. De Pree, and B. J. M. Heijmen, "Inter-fraction bladder filling variations and time trends for cervical cancer patients assessed with a portable 3-dimensional ultrasound bladder scanner q," Radiother. Oncol., vol. 89, no. 2, pp. 172-179, 2008.

[22] I. M. Jürgenliemk-Schulz, M. Z. Toet-Bosma, G. a P. de Kort, H. W. R. Schreuder, J. M. Roesink, R. J. H. a Tersteeg, and U. a van der Heide, "Internal motion of the vagina after hysterectomy for gynaecological cancer.," Radiother. Oncol., vol. 98, no. 2, pp. 244-8, Feb. 2011.

[23] E. a White, K. K. Brock, D. a Jaffray, and C. N. Catton, "Inter-observer variability of prostate delineation on cone beam computerised tomography images.,” Clin. Oncol. (R. Coll. Radiol)., vol. 21, no. 1, pp. 32-8, Feb. 2009. 


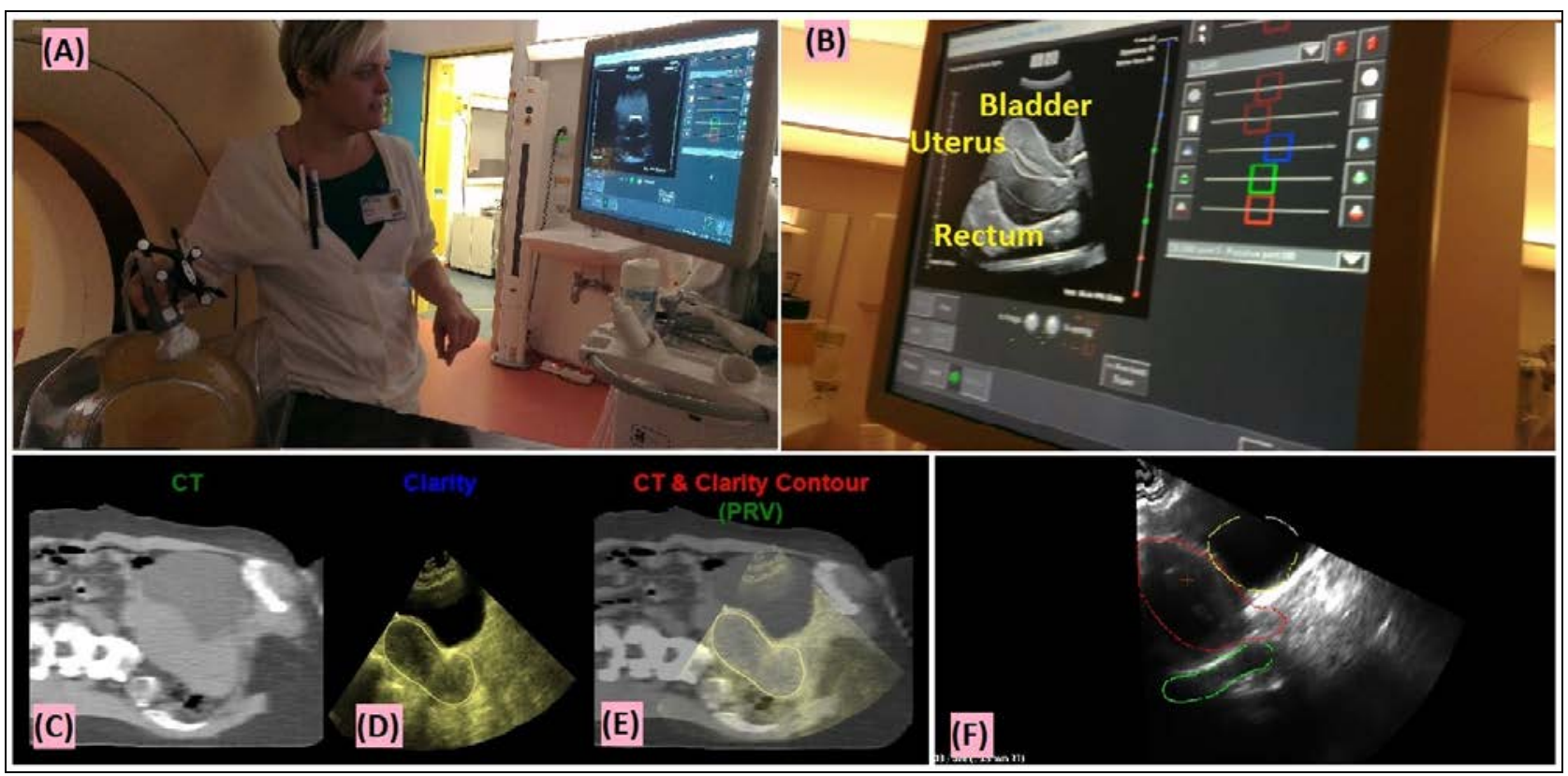

Figure 1. (A) Scanning a patient by sweeping the probe and sliding cranially. (B) The display of the US unit, where the real-time images can be observed. (C), (D), and (E) The fusion of acquired US images with the CT images sets to obtain a planning reference volume (PRV). (F) The US image, acquired in the treatment room is compared with the PRV to detect the uterine shift.

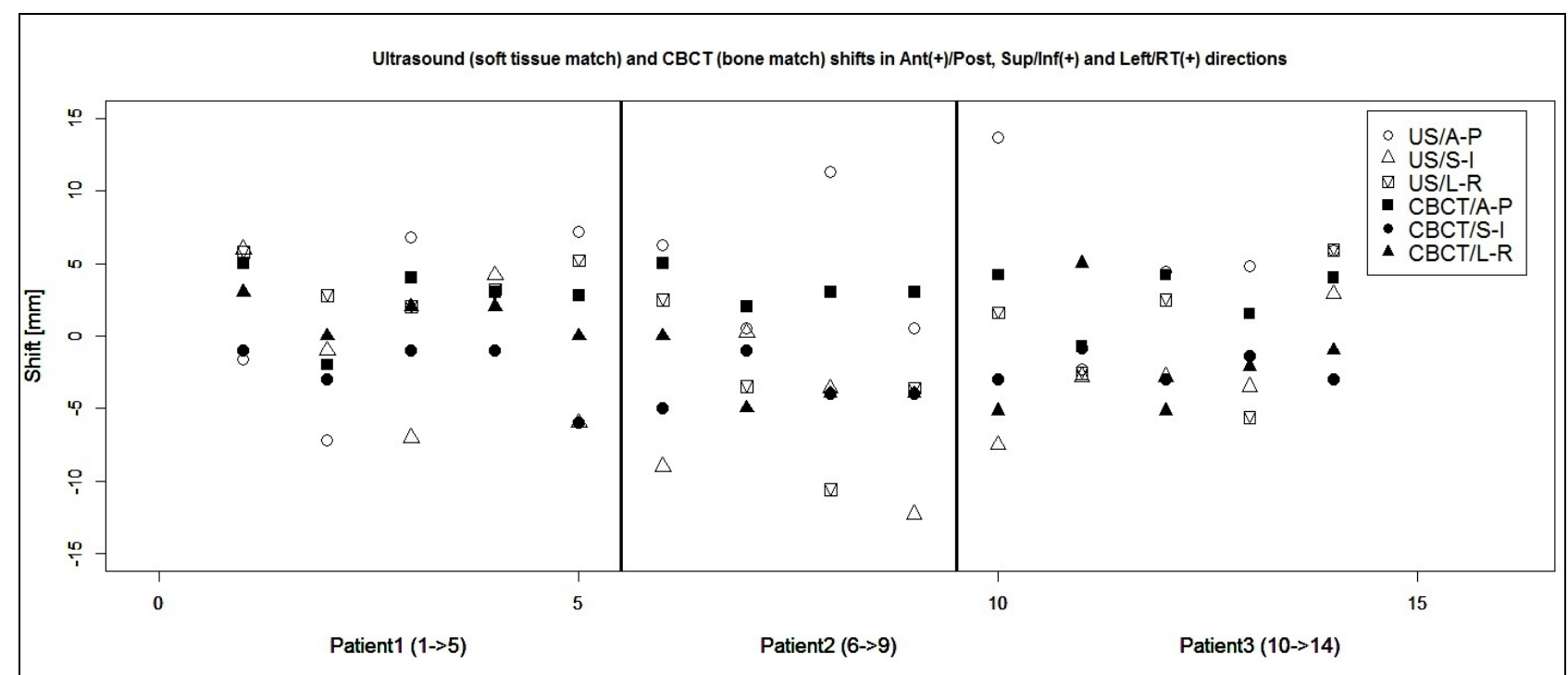

Figure 2. Plot of the uterine shifts in mm (14 weekly scans of three patients) obtained by means of ultrasound imaging (soft tissue matches) and corresponding shifts using CBCT imaging (bone match) for the three cardinal directions; anterior-posterior (AP), superior-inferior (SI), and left-right (LR). 


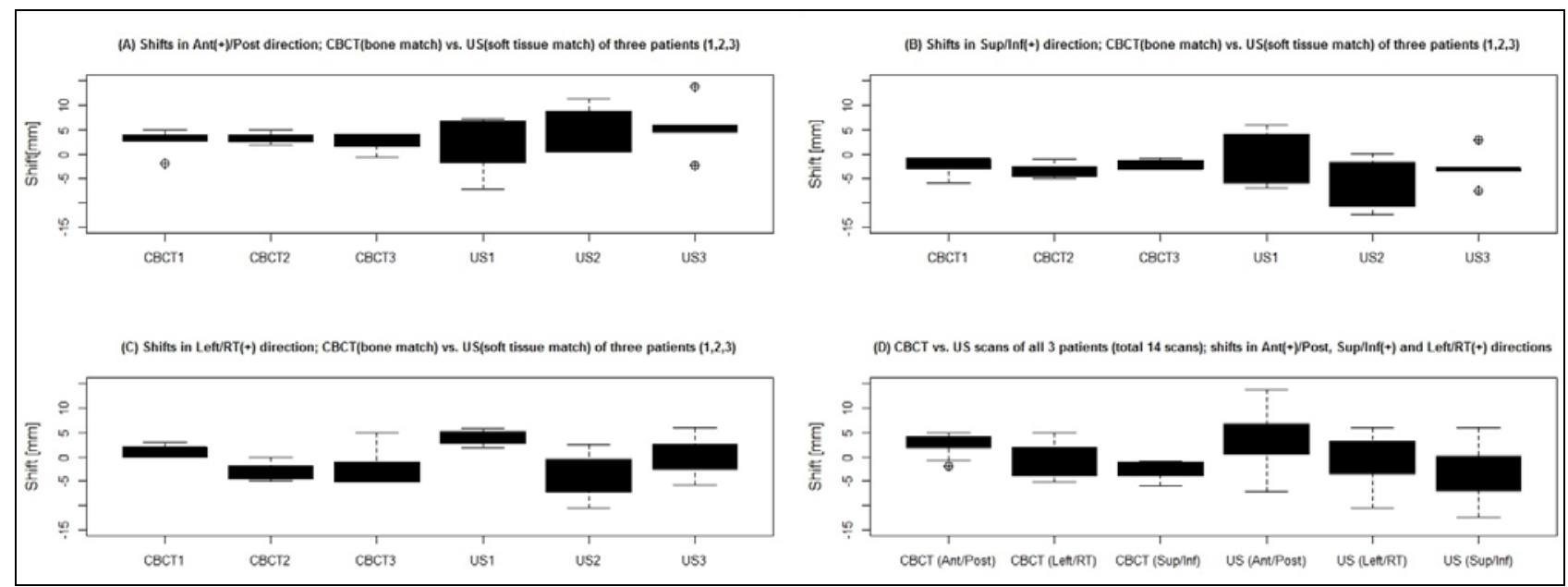

Figure 3. (A), (B), and (C): Box-plots of uterine shifts based on CBCT bone matches and US soft tissue matches for the three patients in the three cardinal directions; LR, AP, and SI. (D): The overall shifts for the patients in all directions.

Table. 1 The overall mean (3 patients, 14 scans), median, and standard deviations of the uterine inter-fractional shifts for ultrasound and CBCT matches in all three directions.

\begin{tabular}{|lcccccc|}
\hline & & \multicolumn{2}{c}{ Ultrasound } & \multicolumn{3}{c|}{ CBCT } \\
\hline & $\begin{array}{l}\text { Anterior/ } \\
\text { Posterior }\end{array}$ & $\begin{array}{l}\text { Superior/ } \\
\text { Inferior }\end{array}$ & $\begin{array}{c}\text { Left/ } \\
\text { Right }\end{array}$ & $\begin{array}{l}\text { Anterior/ } \\
\text { Posterior }\end{array}$ & $\begin{array}{l}\text { Superior/ } \\
\text { Inferior }\end{array}$ & $\begin{array}{l}\text { Left/ } \\
\text { Right }\end{array}$ \\
Median & 4.6 & -3.2 & 2.2 & 3.0 & -3.0 & -0.5 \\
$\begin{array}{l}\text { Mean } \\
( \pm 1 \text { 1SD })\end{array}$ & $3.8( \pm 5.5)$ & $-3.0( \pm 5.2)$ & $0.4( \pm 4.9)$ & $2.8( \pm 2.0)$ & $-2.7( \pm 1.7)$ & $-1.0( \pm 3.3)$ \\
\hline
\end{tabular}


Table2. Values of paired t-test of obtained matching shifts using weekly ultrasound and CBCT scans of cervical cancer patients. The p-values are calculated for a 95\% confidence interval (CI).

\begin{tabular}{|c|c|c|c|c|c|c|c|}
\hline & & $\mathbf{N}$ & $\begin{array}{c}\text { Mean } \\
\text { Of } \\
\text { diff. }\end{array}$ & df & $\mathbf{t}$ & $\begin{array}{c}\text { 95\% CI } \\
\text { (lower/upper) }\end{array}$ & P-value \\
\hline & Direction & & & & & & \\
\hline \multirow[t]{3}{*}{$\begin{array}{c}\text { Patient } \\
1\end{array}$} & $\begin{array}{l}\text { Anterior- } \\
\text { Posterior }\end{array}$ & 5 & -0.92 & 4 & 0.43 & $-6.93 / 5.09$ & 0.692 \\
\hline & $\begin{array}{l}\text { Superior- } \\
\text { Inferior }\end{array}$ & 5 & 1.64 & 4 & 0.72 & $-4.65 / 7.93$ & 0.509 \\
\hline & Left-Right & 5 & 2.4 & 4 & 2.74 & $-0.03 / 4.83$ & 0.052 \\
\hline \multirow[t]{3}{*}{$\begin{array}{c}\text { Patient } \\
2\end{array}$} & $\begin{array}{l}\text { Anterior- } \\
\text { Posterior }\end{array}$ & 4 & 1.40 & 3 & 0.57 & $-6.35 / 9.15$ & 0.606 \\
\hline & $\begin{array}{l}\text { Superior- } \\
\text { Inferior }\end{array}$ & 4 & -2.68 & 3 & 1.22 & $-9.66 / 4.31$ & 0.310 \\
\hline & Left-Right & 4 & -0.55 & 3 & 2.67 & $-7.11 / 6.01$ & 0.807 \\
\hline \multirow[t]{3}{*}{$\begin{array}{c}\text { Patient } \\
3\end{array}$} & $\begin{array}{l}\text { Anterior- } \\
\text { Posterior }\end{array}$ & 5 & 2.67 & 4 & 1.41 & $-2.57 / 7.92$ & 0.230 \\
\hline & $\begin{array}{l}\text { Superior- } \\
\text { Inferior }\end{array}$ & 5 & -0.49 & 4 & 0.28 & $-5.39 / 4.40$ & 0.793 \\
\hline & Left-Right & 5 & 2.05 & 4 & 0.65 & $-6.74 / 10.85$ & 0.552 \\
\hline \multirow[t]{3}{*}{$\begin{array}{c}\text { Three } \\
\text { patients }\end{array}$} & $\begin{array}{l}\text { Anterior- } \\
\text { Posterior }\end{array}$ & 14 & 1.03 & 13 & 0.84 & $-1.60 / 3.65$ & 0.414 \\
\hline & $\begin{array}{l}\text { Superior- } \\
\text { Inferior }\end{array}$ & 14 & -0.36 & 13 & 0.29 & $-2.96 / 2.25$ & 0.773 \\
\hline & Left-Right & 14 & 1.43 & 13 & 1.14 & $-1.29 / 4.16$ & 0.276 \\
\hline
\end{tabular}
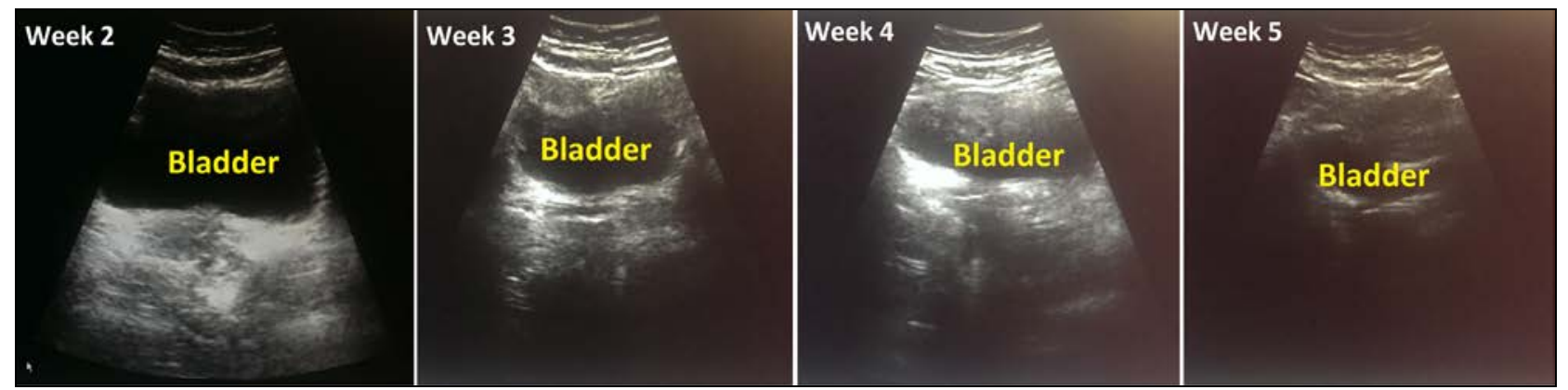

Figure. 5 The bladder volume reduction in patient 1 from week 2 to week 5 of treatment. 